\title{
Pulmonary Lymphangitic Carcinomatosis as the Initial and Only Presentation of Gastric Cancer in a Young Male and Literature Review
}

Dandan Li ( $\nabla x x$ lidan@126.com )

Henan Provincial People's Hospital https://orcid.org/0000-0002-1085-9180

Zhenhua Yuan

Henan Provincial People's Hospital

Haibo Wang

Henan Provincial People's Hospital

Xudong Zhang

Henan Provincial People's Hospital

Xiaoju Zhang

Henan Provincial People's Hospital

\section{Research Article}

Keywords: pulmonary lymphangitic carcinomatosis, malignant lung disease, interlobular septa, differential diagnosis

Posted Date: April 22nd, 2021

DOI: https://doi.org/10.21203/rs.3.rs-441488/v1

License: (c) (i) This work is licensed under a Creative Commons Attribution 4.0 International License. Read Full License 


\section{Abstract}

\section{Background}

Pulmonary lymphangitic carcinomatosis (PLC) is a malignant lung disease characterized by metastatic tumor lesions in the lung lymphatic vessels with a poor prognosis. Early diagnosis is the key to improve the outcome. However, when PLC is the first manifestation of patients without a known malignancy, it often leads to delayed diagnosis and treatment, and even fatal consequences due to non-specific symptoms. Here, we describe a young male presenting PLC as the first and only manifestation followed by diagnosis of gastric adenocarcinoma and systemically summarized previously reported clinical properties of PLC cases in the literature.

\section{Case presentation}

A 32 years old male presented nonproductive cough for 20 days and progressive exertional dyspnea in a week. He was diagnosed with pneumonia and received antibiotics for almost 3 weeks without any improvement. Chest computed tomography showed multiple nodules and thickened interlobular septa in bilateral lung. PET/CT revealed a primary gastric tumor with PLC and the biopsy of the cervical lymph node confirmed a poorly metastatic differentiated gastric adenocarcinoma. The patient's general condition deteriorated rapidly and he developed respiratory failure, requiring non-invasive mechanical ventilation on day 9 after admission. Chemotherapy was given to the patient on the tenth day. However, few hours after receiving the first dose, the patient died of respiratory failure. It was only one month from the onset of symptoms to death of our case.

\section{Conclusions}

Patients presenting PLC as the first manifestation of an unknown malignancy carry a bleak prognosis. PLC be considered for differential diagnosis in patients who present with dyspnea, dry cough with or without loss of weight. Particular attentions need to be given to patients, especially young ones without histories of malignancy, whose chest imaging exhibits thickened interlobular septa. While the stomach, lung and prostate are the most likely origins of the primary tumors, patients with PLC derived from prostate cancer may have a better prognosis after anti-cancer treatment.

\section{Background}

Pulmonary lymphangitic carcinomatosis $(\mathrm{PLC})$ refers to the metastatic malignant tumor infiltration of the lung lymphatic vessels secondary to a primary site [1]. It is believed that PLC occurs in the $6-8 \%$ of the intrathoracic metastasis while exact prevalence not known because its delayed diagnostic consideration often lead to autopsy confirmation [2].

PLC as the initial presentation of malignancy is relatively rare. Dyspnea and cough are the common manifestations associated with PLC [3]. The symptoms are non-specific, patients with no history of tumor 
are easily misdiagnosed as interstitial lung disease [4], pneumonia [5], tuberculosis [6], heart failure [7], pulmonary embolism [8], even diffuse alveolar hemorrhage [9], which usually leads to the delay of diagnosis and treatment. Patients often appear in poor physical condition at the time of definite diagnosis and cannot tolerate anti-tumor therapy. Therefore, early diagnosis and diagnostic awareness of PLC are of paramount importance to improve the prognosis. However, there are no systemic reviews to summary the clinical characteristics of PLC as the first manifestation of malignancy.

Here, we reported a case of a previously healthy young man with PLC as the first and only manifestation of malignancy, which was initially misdiagnosed as pneumonia. We also systemically summarized previously reported clinical properties of PLC cases in the literature. To best of our knowledge, this is the first complete study to picture the clinical characteristics of patients with PLC as the initial presentation before malignancy diagnosis.

\section{Case Presentation}

A 32 years old male attended our hospital with complaint of nonproductive cough for 20 days and progressive exertional dyspnea in a week. He also complained of chest pain on the right side when coughing violently. The patient was an employee of a company and healthy before this attack, with a history of 15 pack years of smoking. He was diagnosed with pneumonia at the local hospital and received antibiotics. The patient became increasingly ill and had difficulties in breath so he was transferred to our hospital.

Physical examination revealed coarse breath sounds on auscultation and respiratory frequency with 22 times/min. Blood tests showed elevated WBC count $(19,680 / \mu \mathrm{L})$, CRP level $(43.9 \mathrm{mg} / \mathrm{L})$ and reduced hemoglobin $(101 \mathrm{~g} / \mathrm{L})$. The serum LDH level was $616 \mathrm{U} / \mathrm{L}$ and the serum albumin was $30.8 \mathrm{~g} / \mathrm{L}$. Chest computed tomography (CT) scan revealed multiple nodules in both lungs, thickened interlobular and bronchovascular interstitium, bilateral pleural effusions and multiple enlarged lymph nodes in mediastinum (Fig. 1A). The imaging findings, especially lymphadenopathy, suggested a differential diagnosis of tumor. So tumor biomarkers were analyzed and the elevated tumor biomarkers were as follows: AFP, $47.86 \mathrm{ng} / \mathrm{mL}(\mathrm{N}<20 \mathrm{ng} / \mathrm{mL}) ; C E A, 72.7 \mathrm{ng} / \mathrm{mL}(\mathrm{N}<5 \mathrm{ng} / \mathrm{mL}) ; C A-125,287.07 \mathrm{U} / \mathrm{mL}(\mathrm{N}<35$ $\mathrm{U} / \mathrm{mL}) ; \mathrm{CA}-199,56.07 \mathrm{kU} / \mathrm{L}(\mathrm{N}<35 \mathrm{kU} / \mathrm{L})$. On day 3, the patient's breathing became more difficult. Arterial blood gas analysis with supplemental oxygen delivered via nasal catheter at $3 \mathrm{~L} / \mathrm{min}$ revealed the following: $\mathrm{pH}, 7.446$; arterial carbon dioxide tension $\left(\mathrm{PCO}_{2}\right), 51.9 \mathrm{mmHg}$; arterial oxygen tension $\left(\mathrm{PO}_{2}\right)$, $61.9 \mathrm{mmHg}$; and arterial oxygen saturation $\left(\mathrm{SaO}_{2}\right), 91.6 \%$. Ultrasound-guided fine needle aspiration biopsy of the cervical lymph node was performed on the fifth day and revealed the presence of metastatic poorly differentiated gastric adenocarcinoma (Fig. 1B). 18F-FDG PET/CT imaging confirmed the primary tumor at the lesser curvature of the stomach (Fig. 1C, D and E) with diffuse lung lymphatic metastasis as well as skeletal metastases (Fig. 1C, F and G). In spite of patient's poor physical condition, by considering the patient's young age, previous health and the desire of his family, we used the chemotherapy scheme of oxaliplatin, docetaxel combined with fluorouracil for the gastric cancer on the 
tenth day. However, few hours after receiving the first dose, the patient died of respiratory failure despite receiving noninvasive mechanical ventilation and placed on $100 \%$ oxygen.

\section{Discussion And Conclusions}

PLC, as the only clinical manifestation of patients without a history of malignant tumors, is relatively rare, so it is easy to be misdiagnosed. However, literature survey showed that there are many case reports rather than system reviews or case series with a large number of patients so far.

To summarize the clinical characteristics of patient with PLC as the first manifestation and enhance the diagnostic awareness, we searched PubMed to screen PLC related literature from inception to 12 October 2020. No language restrictions were applied. We also manually researched the references for eligible articles. The included studies should contain at least the following clinical information: gender, age, chief complaint/pulmonary symptoms, diagnosis methods and definite/probable primary tumor. Published abstracts involving these data were also included. Case series were excluded if the above information had not been documented for each case. We finally identified 78 publications comprising 96 patients with PLC as the initial presentation by reviewing and assessing the searched articles, including 66 full-text studies [4-6, 8-70] and 12 abstracts [71-82]. The search strategy (Supplementary Table 1, Fig. 1) and flow diagram of the study (Supplementary Fig. 2) were shown in the supplementary information files. We then pooled data of 97 patients including our case to further analyze the clinical features of the patients. To evaluate the efficacy of antitumor therapy, we defined the treatment was effective if the patients survived after receiving 4 cycles of chemotherapy or an improvement was reported in the study.

\section{Primary Site, Gender And Age}

The mean age of the 97 patients was $48.3 \pm 18.1$ years (range 7 to 88 years) and the majority of the patients were males $(n=61,62.9 \%)$. The top three common primary malignancy sites were stomach $(n=$ $34,35.1 \%)$, lung $(n=19,19.6 \%)$ and prostate $(n=15,15.5 \%)$ (Fig. 2, Table 1). More than half (50/97) of the primary tumors were originated from digestive system, while the live, gallbladder and choledochal cyst were relatively uncommon. The youngest patient was a 7 year-old boy with kidney cancer [71], and the oldest one was a 88 years old female with lung cancer [6]. 19.6\% of the patients were found in 51-60 year age group which was most commonly affected, $70.1 \%$ were within the age of 60 years $(n=68)$ and $33 \%$ of the patients $(n=32)$ were under the age of 40 years. 61 patients were males, especially in cases with lung cancer $(15 / 19,78.9 \%)$, while gastric cancer was more common in females $(19 / 34,55.9 \%)$. In view of the primary sites, sex and age, PLC as an initial manifestation probably occurred in young patients with tumors originated from digestive system.

\section{Symptoms and imaging features}

Almost all the patients presented with progressive dyspnea. We further analyzed the chief complaints and imaging features of the cases with full-text. A total of 82 patients including our case were identified. The 
most common chief complaints were dyspnea (90.2\%), dry cough (56.1\%) and loss of weight $(51.2 \%)$, while the most common chest imaging findings were thickened interlobular septa (95.1\%), reticulonodular opacities (37.8\%) and pleural effusion (36.6\%) (Table 2).

\section{The prognosis of PLC}

Among all the patients, 47 cases received anti-tumor treatment including chemotherapy, surgery and endocrine therapy while 44 improved (Table 3 ). Of note, all the patients with prostate tumor were relieved after treatment. Moreover, we further summarized the PLC course of the patients with recorded prognosis (Table 4). Out of the 78 patients, 23 patients died within 2 months after the onset, 5 patients died within 1 month after PLC diagnosis with an overall survival time (OST) more than 2 months. Out of the 3 patients without a definite survival time, one patient died within 1 month after PLC diagnosis and the left two patients were diagnosed by autopsy.

\section{The mechanism of PLC}

Regrettably, there were few basic researches conducted on the pathogenesis of PLC. We only found one preclinical study which showed vascular endothelial growth factor-C (VEGF-C) facilitated the induction of lymphangiogenesis and expansion of already disseminated cancer cells throughout the lung tissue in vivo, moreover, the metastatic breast cancer cells in the lung expressed high levels of VEGF-C in patients with PLC. A clinical meta-analysis showed ALK-rearranged NSCLC was more likely to have PLC, pleural metastasis and pleural effusion compared with ALK/EGFR-negative NSCLC95. These data imply that there may be some regulatory factors in the occurred of the PLC. Taking together, there is a great gap between fundamental researches in particular molecular aspects and clinical practice on the mechanism of PLC.

In conclusion, PLC can an initial manifestation of the malignancy. The most common symptoms are dyspnea, dry cough and loss of weight, while the common imaging features are thickened interlobular septa, reticulonodular opacities and pleural effusion. PLC should be considered when patients present with the above clinical features and fail to response to the treatment base on the initial diagnosis, especially in the young males. Stomach, lung and prostate should be the focus area for identifying primary tumor. However, the prognosis of PLC is so far poor, but the patients with prostate cancer showed good response to the anti-tumor therapy. For future, detailed studies are required to find the underlying mechanisms and special intervention targets of PLC.

\section{Abbreviations}

PLC

Pulmonary lymphangitic carcinomatosis

CT

Computed tomography

OST

overall survival time 
DPLC

the diagnosis of PLC

\section{Declarations}

\section{Availability of the data and materials}

All data generated or analyzed during this study are included in this article and its supplementary information file.

\section{Funding}

This study was supported by Doctoral Scientific Research Foundation of Henan Provincial People's Hospital (ZC20190166) and Zhongyuan Science and Technology Innovation Leading Talents Program (194200510021).

\section{Contributions}

Li DD was responsible for this patient's treatment, conducted a literature search, data analysis and manuscript writing. Yuan $\mathrm{ZH}$ and Wang HB were involved in reviewing and accessing the literature. Zhang XD and Zhang XJ wrote the final version of the manuscript. The authors read and approved the final manuscript.

\section{Ethics approval and consent to participate}

This is a case report. The Institutional Review Board at the Henan Provincal People's Hospital has confirmed that no ethical approval is required. Consent was obtained from the patient for participation in this study.

\section{Consent for publication}

We obtained the patient's consent for publication of this case report.

\section{Competing interests}

The authors declare that they have no competing interests.

\section{References}

1. Doyle L. Gabriel Andral (1797-1876) and the first reports of lymphangitis carcinomatosa. J R Soc Med. 1989;82:491-3.

2. Bruce DM, Heys SD, Eremin O. Lymphangitis carcinomatosa: a literature review. J R Coll Surg Edinb. 1996;41:7-13. 
3. Klimek M. Pulmonary lymphangitis carcinomatosis: systematic review and meta-analysis of case reports, 1970-2018. Postgrad Med. 2019;131:309-18.

4. Cohen O, Leibovici L, Wysenbeek Al. Carcinoma of the prostate presenting as interstitial lung disease. Respiration. 1987;51:158-60.

5. Sood N, Bandarenko N, Paradowski LJ. Case 2: acute respiratory failure secondary to lymphangitic carcinomatosis. J Clin Oncol. 2000;18:229-32.

6. Hensley P, Hilal T. Maintaining sharp focus on a grainy film: miliary pattern in an elderly woman with acute respiratory failure. 2015, 2015.

7. Koenigs KP, Campbell DR, Magrina J, Ruth WE. Pulmonary lymphangitic carcinomatosis from vaginal carcinoma presenting as congestive heart failure. Obstet Gynecol. 1983;61:760-3.

8. Koutaki Y, Nii T, Eguchi K, Kousa K, Niimura H. Carcinomatous lymphangitis mimicking pulmonary thromboembolism. Jpn Circ J. 2001;65:683-4.

9. Chin E, Yeap BY, Shaw AT, Gainor JF, Higo H. Pulmonary lymphangitic carcinomatosis from gallbladder cancer mimicking diffuse alveolar haemorrhage. Cancers (Basel). 2020;8:e00540.

10. Saccomanno G, Kleinschmidt CC, Murphy P. A case of lymphangitic carcinoma of the lung diagnosed by sputum smear examination. Dis Chest. 1950;17:273-9.

11. Ross CF. Diffuse pulmonary lymphatic carcinomatosis due to a renal carcinoma showing cytoplasmic inclusions. Br J Urol. 1951;23:263-6.

12. Hauser TE, Steer A. Lymphangitic carcinomatosis of the lungs: six case reports and a review of the literature. Ann Intern Med. 1951;34:881-98.

13. Chandler GN, Telling M. Lymphangitis carcinomatosa. Br Med J. 1952;2:639-41.

14. Cihak RJ. A tangled web. Jama. 1970;212:2090-1.

15. Lome LG, John T. Pulmonary manifestations of prostatic carcinoma. J Urol. 1973;109:680-5.

16. Aranda C, Sidhu G, Sasso LA, Adams FV. Transbronchial lung biopsy in the diagnosis of lymphangitic carcinomatosis. Cancer. 1978;42:1995-8.

17. Yang SP, Lin CC. Lymphangitic carcinomatosis of the lungs. The clinical significance of its roentgenologic classification. Chest. 1972;62:179-87.

18. Tesar PJ, Goy J, Maynard J. Lymphangitis carcinomatosa. Med J Aust. 1981;1:80-1.

19. Heffner JE, Duffey DJ, Schwarz MI. Massive pleural effusions from prostatic lymphangitic carcinomatosis: resolution with endocrine therapy. Arch Intern Med. 1982;142:375-6.

20. Case records of the Massachusetts General Hospital. Weekly clinicopathological exercises. Case 341983. A 32-year-old man with testicular enlargement and pulmonary intravascular carcinoma. $\mathrm{N}$ Engl J Med. 1983;309:477-87.

21. Dennstedt FE, Greenberg SD, Kim HS, Weilbaecher DG, Bloom K. Pulmonary lymphangitic carcinomatosis from occult stomach carcinoma in young adults: an unusual cause of dyspnea. Chest. 1983;84:787-8. 
22. Simpson FG, King HA, Whelan P, Cooke NJ. Prostatic carcinoma presenting with respiratory symptoms: response to orchidectomy. Thorax. 1984;39:552-3.

23. Solomons K, Polakow R, Marchand P. Diffuse malignant mesothelioma presenting as bilateral malignant lymphangitis. Thorax. 1985;40:682-3.

24. Desigan G, Wang M, Wofford B, Dunn GD, Vaughan S. Occult gastric cancer manifested by progressive shortness of breath in a young adult. South Med J. 1986;79:1173-6.

25. Fend F, Gruber U, Fritzsche H, Rothmund J, Breitfellner G, Mikuz G. Occult papillary carcinoma of the thyroid with pulmonary lymphangitic spread diagnosed by lung biopsy. Klin Wochenschr. 1989;67:687-90.

26. Aiello VD, Mansur AJ, Lopes EA, Bellotti G, Pileggi F. Severe pulmonary hypertension due to carcinomatous lymphangitis of the lungs associated with unsuspected gastric cancer. Am Heart $\mathrm{J}$. 1988;116:197-8.

27. Liam CK, Looi LM, Pailoor J, Alhady SF. Dyspnoea in young adults due to pulmonary lymphangitic carcinomatosis from gastric carcinoma. Ann Acad Med Singap. 1989;18:713-6.

28. Mestitz H, Pierce RJ, Holmes PW. Intrathoracic manifestations of disseminated prostatic adenocarcinoma. Respir Med. 1989;83:161-6.

29. Wong SY. Bilateral massive ovarian oedema-report of a case due to lymphangiitis carcinomatosa. Virchows Arch A Pathol Anat Histopathol. 1989;414:355-8.

30. Fukuda M, Sasaki Y, Sakamoto M, Noguchi M, Saijo N. Primary lung cancer in an 18-year-old boy: case report. Jpn J Clin Oncol. 1990;20:177-81.

31. Shimura S, Takishima T. Bronchorrhea from diffuse lymphangitic metastasis of colon carcinoma to the lung. Chest. 1994;105:308-10.

32. Ahuja S, Ernst H. Dormant metastases in medullary thyroid carcinoma. A case report. Exp Clin Endocrinol. 1991;98:37-41.

33. Miseria S, Torresi U, Menichetti ET, Tummarello D, Baldelli S, Murer B, Cellerino R. Lymphangitic carcinomas of the lung as presentation of prostatic cancer. A case report. Tumori. 1991;77:86-9.

34. Verstraeten A, Sault MC, Wallaert B, Lemonnier P, Gosselin B, Tonnel AB. Metastatic prostatic adenocarcinoma-diagnosed by bronchoalveolar lavage and tumour marker determination. Eur Respir J. 1991;4:1296-8.

35. Perez-Lasala G, Cannon DT, Mansel JK, McGehee RP, Allen KG. Case report: lymphangitic carcinomatosis from cervical carcinoma-an unusual presentation of diffuse interstitial lung disease. Am J Med Sci. 1992;303:174-6.

36. Fujita J, Yamagishi Y, Kubo A, Takigawa K, Yamaji Y, Takahara J. Respiratory failure due to pulmonary lymphangitis carcinomatosis. Chest. 1993;103:967-8.

37. Smith KG, Fairley KF, Allan PE. Lymphangitis carcinomatosa on renal biopsy. Nephron. 1994;67:3723. 
38. Morillas MJ, López J, García-Cano J, Pérez Vigara G, Peña J. González Martín JA. [Pulmonary carcinomatous lymphangitis as initial manifestation of gastric cancer]. Rev Esp Enferm Dig. 1996;88:379-80.

39. Walgraeve N, Hertveldt K, Van Renterghem D, Van Den Eeckhaut A, De Geeter F. Perfusion lung scan in lymphangitic carcinomatosis. Clin Nucl Med. 2001;26:953-4.

40. Gerstenkorn C, Thomusch O. Transmission of a pancreatic adenocarcinoma to a renal transplant recipient. Clin Transplant. 2003;17:473-6.

41. Molina DK, Valente PT. Lymphangitic spread of hepatocellular carcinoma. Arch Pathol Lab Med. 2003;127:e11-3.

42. Gupta PR, Joshi N, Meena RC, Ali M. Asymptomatic lymphangitis carcinomatosis due to squamous cell lung carcinoma. Indian J Chest Dis Allied Sci. 2005;47:121-3.

43. Martynychen MG, Rabelo LM, Silva RL, Escuissato DL. Carcinomatous lymphangitis as the initial manifestation of ovarian adenocarcinoma. J Bras Pneumol. 2007;33:609-11.

44. Tuon FF, Miyaji KT, de Vidal PM, da Silva LF, Kono A, Franca FO. Simultaneous occurrence of pulmonary tuberculosis and carcinomatous lymphangitis. Rev Soc Bras Med Trop. 2007;40:76-7.

45. Kirk JE, Kumaran M. Lymphangitis carcinomatosa as an unusual presentation of renal cell carcinoma: a case report. J Med Case Rep. 2008;2:19.

46. Rossi G, Cadioli A, Casali C. Double synchronous pulmonary lymphatic-related lesions. Int J Surg Pathol. 2008;16:430-2.

47. Thomas A, Lenox R. Pulmonary lymphangitic carcinomatosis as a primary manifestation of colon cancer in a young adult. Cmaj. 2008;179:338-40.

48. Garcia Sevila R, Barroso E, Martin C, Aranda I, Romero S. Lymphangitic carcinomatosis as a cause of malignant transient pleural transudate. Case Rep Med 2009, 2009:598741.

49. Raja A, Seshadri RA, Sundersingh S. Lymphangitis carcinomatosa: report of a case and review of literature. Indian J Surg Oncol. 2010;1:274-6.

50. Gicquello A, Delpierre C, Bouchindhomme B, Mouquet F, Wallaert B. [Atypical unilateral insterstitial disease]. Rev Mal Respir. 2011;28:664-7.

51. Otsubo K, Kubo N, Nakashima N, Izumi M, Nakamori M, Koto H. A juvenile case of pulmonary lymphangitic carcinomatosis caused by sigmoid colon cancer with a component of micropapillary carcinoma. Intern Med. 2011;50:2361-5.

52. Moubax K, Wuyts W, Vandecaveye V, Prenen H. Pulmonary lymphangitic carcinomatosis as a primary manifestation of gastric carcinoma in a young adult: a case report and review of the literature. BMC Res Notes. 2012;5:638.

53. Lin WR, Lai RS. Pulmonary lymphangitic carcinomatosis. Qjm. 2014;107:935-6.

54. Hibino M, Ito R, Kondo T. Hypereosinophilic Pulmonary Carcinomatous Lymphangitis Mimicking Acute Eosinophilic Pneumonia. Am J Respir Crit Care Med. 2015;192:761-2. 
55. Khachekian A, Shargh S, Arabian S. Pulmonary lymphangitic carcinomatosis from metastatic gastric adenocarcinoma: case report. J Am Osteopath Assoc. 2015;115:332-7.

56. Jinnur PK, Pannu BS, Boland JM, lyer VN. Occult pulmonary lymphangitic carcinomatosis presenting as 'chronic cough' with a normal HRCT chest. Ann Med Surg (Lond). 2016;6:77-80.

57. Ağca M, Akyıl FT, Hörmet M, Akman O, Akman C, Şen A, Sevim T. A Rare Case of Progressive Dyspnea and Bilateral Lung Infiltration in a Young Male. Turk Thorac J. 2017;18:96-9.

58. Bhattacharya PK, Jamil M, Khonglah Y, Roy A, Subrahmanya MV. A Rare Case of Pulmonary Lymphangitic Carcinomatosis in a Young Adult with Carcinoma Stomach. J Clin Diagn Res. 2017;11:Od07-od09.

59. Hibino M, Maeda K, Horiuchi S, Fukuda M, Kondo T. Pulmonary lymphangitic carcinomatosis with ground-glass opacities as presentation of prostate cancer. Respirol Case Rep. 2018;6:e00347.

60. Okayama M, Kanemitsu Y, Oguri T, Asano T, Fukuda S, Ohkubo H, Takemura M, Maeno K, Ito Y, Niimi A. A Rare Case of Isolated Chronic Cough Caused by Pulmonary Lymphangitic Carcinomatosis as a Primary Manifestation of Rectum Carcinoma. Intern Med. 2018;57:2709-12.

61. Shi AW, Shen XF, Ding HJ, Liu YQ, Meng L, Kalionis B. Pancreatic carcinoma underlying a complex presentation in late pregnancy: a case report. J Med Case Rep. 2018;12:369.

62. Tang VD, Campbell P, Pattison DA. Lymphangitic Carcinomatosis From Prostate Cancer Identified With Gallium-68 Prostate-specific Membrane Antigen Positron Emission Tomography Imaging. Urology. 2018;114:e1-2.

63. Yuan H, Sima B, Belhassine M, Papakrivopoulou E, Venet C, Mestdagh C, Schroeven M. Gastric adenocarcinoma revealed by atypical pulmonary lymphangitic carcinomatosis. Thorac Cancer. 2018;9:1207-12.

64. Aslam HM, Zhi C, Nadeem M, Arsalan M, Wallach SL. A Case of Rapidly Deteriorating Lymphangitic Carcinomatosis in a Patient with Stage IV Pancreatic Cancer. Cureus. 2019;11:e4421.

65. Grosse A, Grosse C. Lung Adenocarcinoma Manifesting with Lymphangitic Spread and Psammoma Bodies, Harboring a HER2 Exon 20 Insertion Mutation (p.A745_G746insYVMA). J Thorac Oncol. 2019;14:e52-4.

66. Hecimovic A, Jakopovic M, Vukic Dugac A, Dzubur F, Samarzija M. Metastatic cancer mimics interstitial lung disease. Cases when we need fast diagnosis and treatment. Monaldi Arch Chest Dis 2019, 89.

67. Toshima H, Ikusue T, Hisamatsu A, Kobayashi K, Shimada K. Two cases of lymphangitic carcinomatosis as the primary symptom of colorectal carcinoma that achieved complete remission using combination anti-EGFR antibody therapy. Onco Targets Ther. 2019;12:2089-93.

68. Whittington JR, Whitcombe DD, Eads LE, Jeffus SK, Quick CM, Wendel PJ, Magann EF. Signet Ring Cell Carcinoma with Lymphangitic Carcinomatosis in Pregnancy: A Case Report of an Unexpected Maternal Death and Review of the Literature. Am J Case Rep. 2019;20:1888-91.

69. Kitaguchi Y, Hayama M, Nojima S, Tsuda T, Takeda K, Nakatani A, Obata S, Morii E, Inohara H, Petnak T, et al. Initial diagnosis and successful treatment of pulmonary tumor embolism manifesting as the 
first clinical sign of prostatic adenocarcinoma. Ear Nose Throat J. 2020;31:101163.

70. Viljoen N, Hendricks M, Panieri E, Aldera AP. Papillary thyroid carcinoma presenting as miliary nodules on chest roentgenogram in the paediatric setting: A case report. Int J Surg Case Rep. 2020;72:322-5.

71. Vanclaire J, Bodart E, Schlesser P, Francotte N, Thiry G, Hainaut H. [Pulmonary carcinomatous lymphangitis and renal adenocarcinoma]. Arch Fr Pediatr. 1990;47:735-6.

72. Chiang YC, Lee $\mathrm{CH}$, Lin PY. Pulmonary lymphangitis carcinomatosa due to adenocarcinoma arising from choledochal cyst: report of an autopsy case. J Formos Med Assoc. 1991;90:860-2.

73. Durieu J, Maignan PA, Copin MC, Wallaert B, Saulnier F, Tonnel AB. [Pulmonary artery hypertension caused by carcinomatous lymphangitis ]. Rev Mal Respir. 1997;14:55-8.

74. Giard RW, van den Tweel JG. [Truth after death]. Ned Tijdschr Geneeskd. 1999;143:2345-7.

75. Scala R, Aronne D, Del Prato B, Montella L, Giacobbe R, Galloro R, Palumbo U. Endobronchial metastasis from stomach carcinoma. Monaldi Arch Chest Dis. 2000;55:6-8.

76. Casallo Blanco S, Marcos Sánchez F, de Matías Salces L, Viana Alonso A, Celdrán Gil J. Núñez Cuerda E. [Lung adenocarcinoma feigning an interstitial lung disease in a 30-year-old man]. An Med Interna. 2007;24:289-91.

77. Yamagishi Y, Okada Y, Ishikawa M, Mizuno A, Katano K, Fujita M. [A case of diffusely infiltrating rectal cancer with pulmonary lymphangitis carcinomatosa successfully treated with mFOLFOX6 chemotherapy as salvage]. Gan To Kagaku Ryoho. 2008;35:1959-63.

78. Koma Y, Matsuoka H, Ryoke T, Koyama M, Fukumitsu K, Kasai Y, Masuya D, Yoshimatsu H, Kitazawa S, Suzuki Y. [A case of pulmonary carcinomatous lymphangitis and multiple pulmonary infarctions from gastric cancer]. Nihon Kokyuki Gakkai Zasshi. 2011;49:577-82.

79. Rashid MM, Ahmed M, Hossain D, Sarwar MG, Zaman Y, Nigar A, Hassan MR. Pulmonary metastases of a papillary adeno-carcinoma of ovary in a pregnant lady. Mymensingh Med J. 2012;21:175-8.

80. Okamoto E, Takagi K, Tamura A, Kondo M, Hanada S, Sakuranaka H, Ochi J, Tanaka M, Tei S, Ichioka $\mathrm{M}$, Shibayama T. [A case of advanced gastric cancer with carcinomatous lymphangitis of the lung treated with docetaxel and S-1 combination chemotherapy]. Gan To Kagaku Ryoho. 2013;40:2247-9.

81. Ré DP, Cazaux A, Cambursano VH, Zaya A, Cortez JR. [Pulmonary carcinomatous lymphangitis: presentation as acute pneumopathy. Report of two cases]. Rev Fac Cien Med Univ Nac Cordoba. 2013;70:31-3.

82. Ishida H, Yokota K, Suzuki Y, Endo E, Ogasawara H, Kosaka S, Minegishi M, Iwane T, Yokoyama S, Otomo $\mathrm{H}$, Sasano $\mathrm{H}$. [A rare case of lymphangitis carcinomatosa of the lung due to primary pulmonary adenocarcinoma with intestinal differentiation successfully treated with chemotherapy]. Gan To Kagaku Ryoho. 2015;42:371-4.

\section{Tables}

Table 1. Primary site in relation with sex and age 


\begin{tabular}{|c|c|c|c|c|c|c|c|c|c|c|c|}
\hline \multirow{2}{*}{$\begin{array}{l}\text { Primary } \\
\text { site }\end{array}$} & \multirow[t]{2}{*}{ Sex } & \multicolumn{3}{|c|}{ Age, years } & \multirow[b]{2}{*}{$\begin{array}{l}31- \\
40\end{array}$} & \multirow[b]{2}{*}{$\begin{array}{l}41- \\
50\end{array}$} & \multirow[b]{2}{*}{$\begin{array}{l}51- \\
60\end{array}$} & \multirow[b]{2}{*}{$\begin{array}{l}61- \\
70\end{array}$} & \multirow[b]{2}{*}{$\begin{array}{l}71- \\
80\end{array}$} & \multirow[b]{2}{*}{$\begin{array}{l}81- \\
90\end{array}$} & \multirow[b]{2}{*}{ Tota } \\
\hline & & $0-10$ & $\begin{array}{l}11- \\
20\end{array}$ & $\begin{array}{l}21- \\
30\end{array}$ & & & & & & & \\
\hline \multirow[t]{2}{*}{ Stomach } & $M$ & & & 5 & 3 & 4 & & 3 & & & 15 \\
\hline & $F$ & & & 5 & 3 & 2 & 5 & 2 & 2 & & 19 \\
\hline \multirow[t]{2}{*}{ Lung } & $M$ & & 1 & 1 & & 3 & 4 & 3 & 3 & & 15 \\
\hline & $F$ & & & & 1 & 1 & & 1 & & 1 & 4 \\
\hline Prostate & $M$ & & & & & & 5 & 7 & 2 & 1 & 15 \\
\hline \multirow{2}{*}{$\begin{array}{l}\text { Colon \& } \\
\text { Rectum }\end{array}$} & $M$ & & & & 1 & 1 & & 2 & & & 4 \\
\hline & $F$ & & & 1 & 2 & & 1 & & 1 & & 5 \\
\hline \multirow[t]{2}{*}{ Pancreas } & $M$ & & & & & & 3 & & & & 3 \\
\hline & $F$ & & & 1 & & & & & & & 1 \\
\hline \multirow[t]{2}{*}{ Thyroid } & $M$ & & 1 & & & & & & & & 1 \\
\hline & $F$ & & & 1 & 1 & & & & & & 2 \\
\hline Ovary & $F$ & & & 1 & & 2 & & & & & 3 \\
\hline Kidney & $M$ & 1 & & & & 1 & 1 & & & & 3 \\
\hline Liver & $M$ & & & & & 1 & & & & & 1 \\
\hline Breast & $F$ & & & & & 1 & & & & & 1 \\
\hline Cervix & $F$ & & & & 1 & & & & & & 1 \\
\hline Gallbladder & M & & & & & & & & & 1 & 1 \\
\hline $\begin{array}{l}\text { Choledochal } \\
\text { cyst }\end{array}$ & M & & 1 & & & & & & & & 1 \\
\hline Mediastinum & $M$ & & & 1 & & & & & & & 1 \\
\hline Pleura & $M$ & & & & & 1 & & & & & 1 \\
\hline Total & & 1 & 3 & 16 & 12 & 17 & 19 & 18 & 8 & 3 & 97 \\
\hline
\end{tabular}

Table 2. The chief complaints and imaging features in 82 patients 


\begin{tabular}{|lll|}
\hline Clinical characteristic & No. & Incidence (\%) \\
\hline Chief complaint & & \\
\hline Dyspnea & 74 & 90.2 \\
\hline Dry cough & 46 & 56.1 \\
\hline Loss of weight & 42 & 51.2 \\
\hline Thoracic pain & 16 & 19.5 \\
\hline Productive cough & 15 & 18.3 \\
\hline Fever & 14 & 17.1 \\
\hline Malaise & 14 & 17.1 \\
\hline Hemoptysis & 11 & 13.4 \\
\hline Night sweats & 7 & 8.5 \\
\hline Pain of back & 1 & 1.2 \\
\hline Imaging characteristics & & \\
\hline Thickened interlobular septa & 78 & 95.1 \\
\hline Reticulonodular opacities & 31 & 37.8 \\
\hline Pleural effusion & 30 & 36.6 \\
\hline Mediastinal lymphadenopathy & 19 & 23.2 \\
\hline Small nodules & 16 & 19.5 \\
\hline Ground glass opacification & 12 & 14.6 \\
\hline
\end{tabular}

Table 3. Primary site in relation with anti-tumor treatment and therapeutic effect 


\begin{tabular}{|c|c|c|c|c|}
\hline Primary site & Untreatment & Improved/Treatment & Unrecorded & Total \\
\hline Stomach & 18 & $6 / 11$ & 5 & 34 \\
\hline Lung & 6 & $4 / 9$ & 4 & 19 \\
\hline Prostate & 0 & $13 / 13$ & 2 & 15 \\
\hline Colon \& Rectum & 1 & $5 / 7$ & 1 & 9 \\
\hline Pancreas & 4 & & & 4 \\
\hline Thyroid & & $3 / 3$ & & 3 \\
\hline Ovary & & $2 / 2$ & 1 & 3 \\
\hline Kidney & 2 & & 1 & 3 \\
\hline Liver & 1 & & & 1 \\
\hline Breast & 1 & & & 1 \\
\hline Cervix & & $0 / 1$ & & 1 \\
\hline Gallbladder & 1 & & & 1 \\
\hline Choledochal cyst & & & 1 & 1 \\
\hline Mediastinum & & $1 / 1$ & & 1 \\
\hline Pleura & 1 & & & 1 \\
\hline Total & 35 & $34 / 47$ & 15 & 97 \\
\hline
\end{tabular}

Table 4. Prognosis in relation with primary sites of PLC 


\begin{tabular}{|c|c|c|c|c|}
\hline Primary site & Untreatment & Improved/Treatment & Unrecorded & Total \\
\hline Stomach & 18 & $6 / 11$ & 5 & 34 \\
\hline Lung & 6 & $4 / 9$ & 4 & 19 \\
\hline Prostate & 0 & $13 / 13$ & 2 & 15 \\
\hline Colon \& Rectum & 1 & $5 / 7$ & 1 & 9 \\
\hline Pancreas & 4 & & & 4 \\
\hline Thyroid & & $3 / 3$ & & 3 \\
\hline Ovary & & $2 / 2$ & 1 & 3 \\
\hline Kidney & 2 & & 1 & 3 \\
\hline Liver & 1 & & & 1 \\
\hline Breast & 1 & & & 1 \\
\hline Cervix & & $0 / 1$ & & 1 \\
\hline Gallbladder & 1 & & & 1 \\
\hline Choledochal cyst & & & 1 & 1 \\
\hline Mediastinum & & $1 / 1$ & & 1 \\
\hline Pleura & 1 & & & 1 \\
\hline Total & 35 & $34 / 47$ & 15 & 97 \\
\hline
\end{tabular}

Figures 

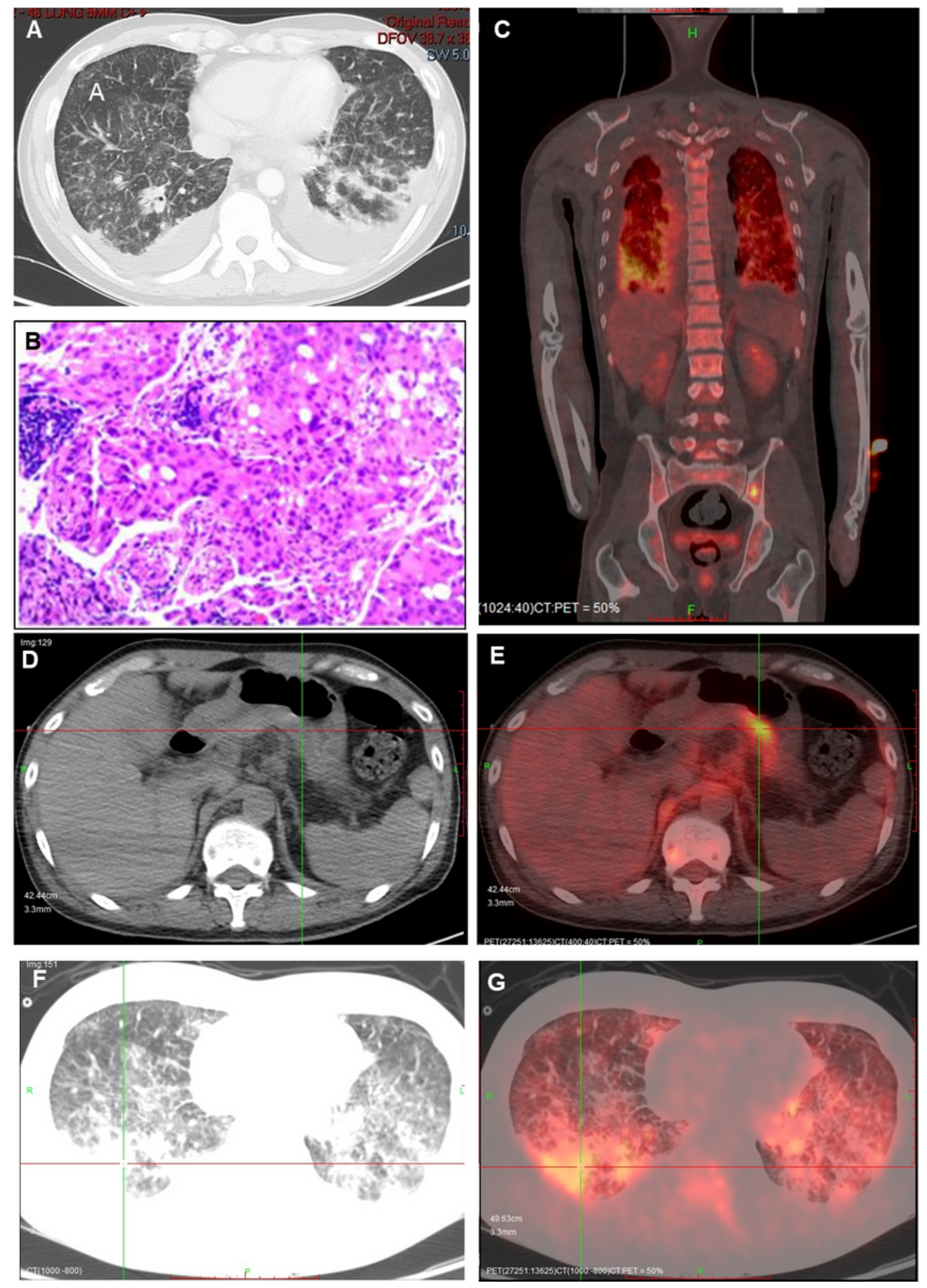

\section{Figure 1}

The imaging findings and biopsy. (A) Chest CT showed diffuse increased reticular markings, reticulonodular shadows and bilateral pleural effusion on admission. (B) The H\&E staining of the biopsy of cervical lymph node showed poorly differentiated adenocarcinoma. (C) Coronary PET-CT revealed increase uptake of 18F-FDG involving bilateral lungs and bones on the sixth day. (D) Axial abdominal CT and corresponding PET-CT (E) showed thickened lesser curvature of the stomach and increased uptake. 
(F) Axial chest CT and corresponding PET-CT (G) showed increased interstitial infiltration and diffuse uptake.

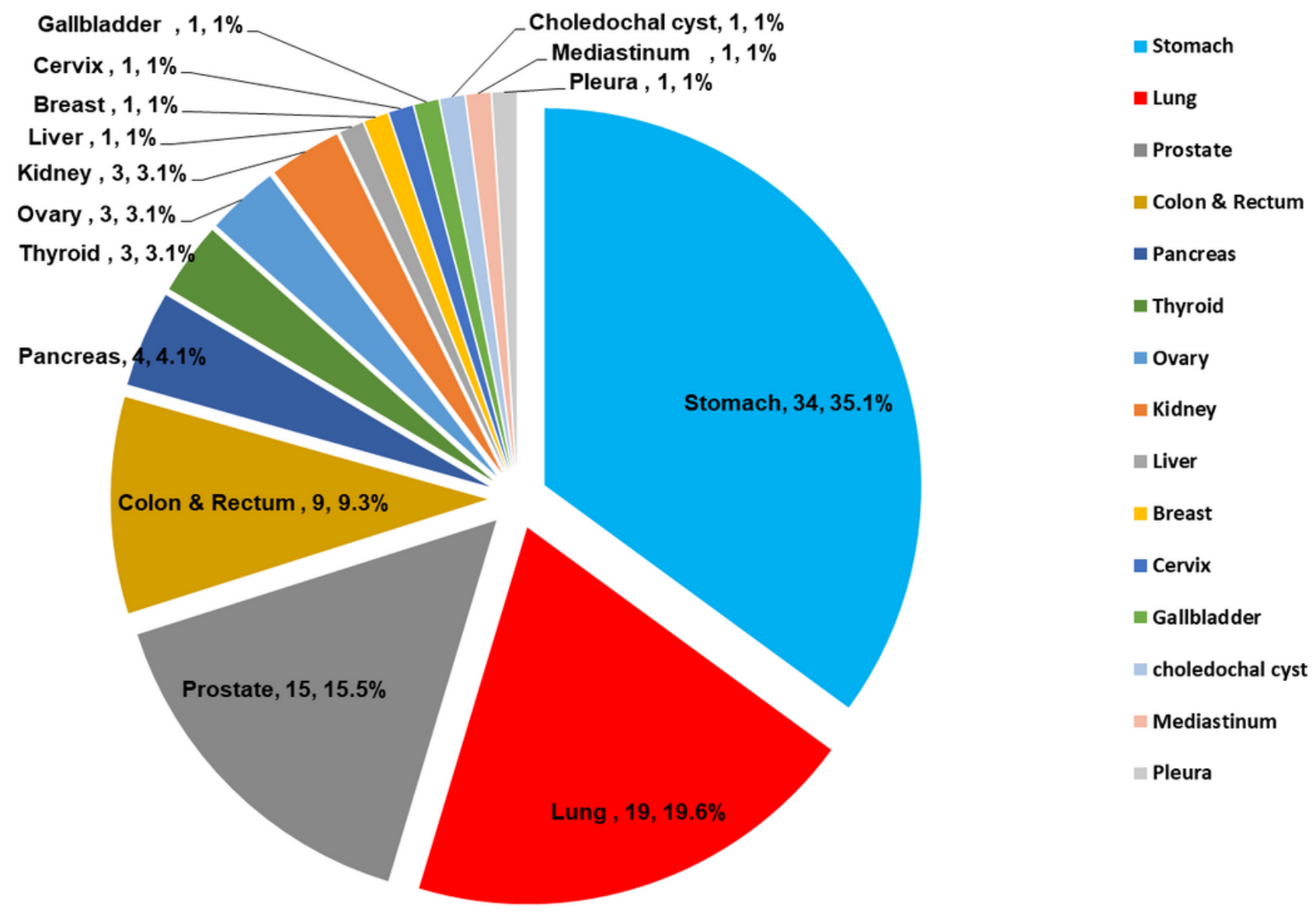

\section{Figure 2}

The composition of primary sites in 97 patients with PLC as the initial presentation of malignancy

\section{Supplementary Files}

This is a list of supplementary files associated with this preprint. Click to download.

- Supplementarydata.docx 